\title{
How can doctors reduce no-shows?
}

\author{
Cite as: CMAJ 2020 February 10;192:E151-2. doi: 10.1503/cmaj.1095842
}

Posted on cmajnews.com on January 24, 2020

\section{Part two of a series on no-shows}

K atherina Yerro battles fatigue and pain from a chronic condition and often cancels medical appointments at the last minute. The day before an appointment, she stays home to conserve energy. Even so, she may still wake up on the day of the appointment feeling too exhausted to operate her electric wheelchair. While she finds doctors don't mind if she misses a first appointment, in rare cases, some have charged fees for subsequent cancellations - once $\$ 20$, another time, $\$ 45$. "That meant I had less money for food those months, which is major because my food budget is tight," Yerro explains.

Many health care providers now charge fees for late cancellations and missed appointments to recoup costs and discourage no-shows. But some argue there are other ways to ensure people show up without penalizing patients.

Leaving aside the potential negative impacts on patients and the care relationship, no-show fees aren't likely to change behaviour, says Mary Jane Hampton, a Halifax-based health care consultant. "Fees assume that there is a kind of conscious decision by the patient not to comply with the expectation of the practice."

This is rarely the case, however. Forgetting an appointment is one of the most common reasons for no-shows, and one Canadian study found that nearly a quarter of patients who didn't show up for appointments felt too sick to attend. Transit issues and childcare obligations were other common barriers.

Patients who don't show up for appointments tend to be younger, poorer and live farther away from the doctor than those who attend consistently. Some patients may be unaware that they

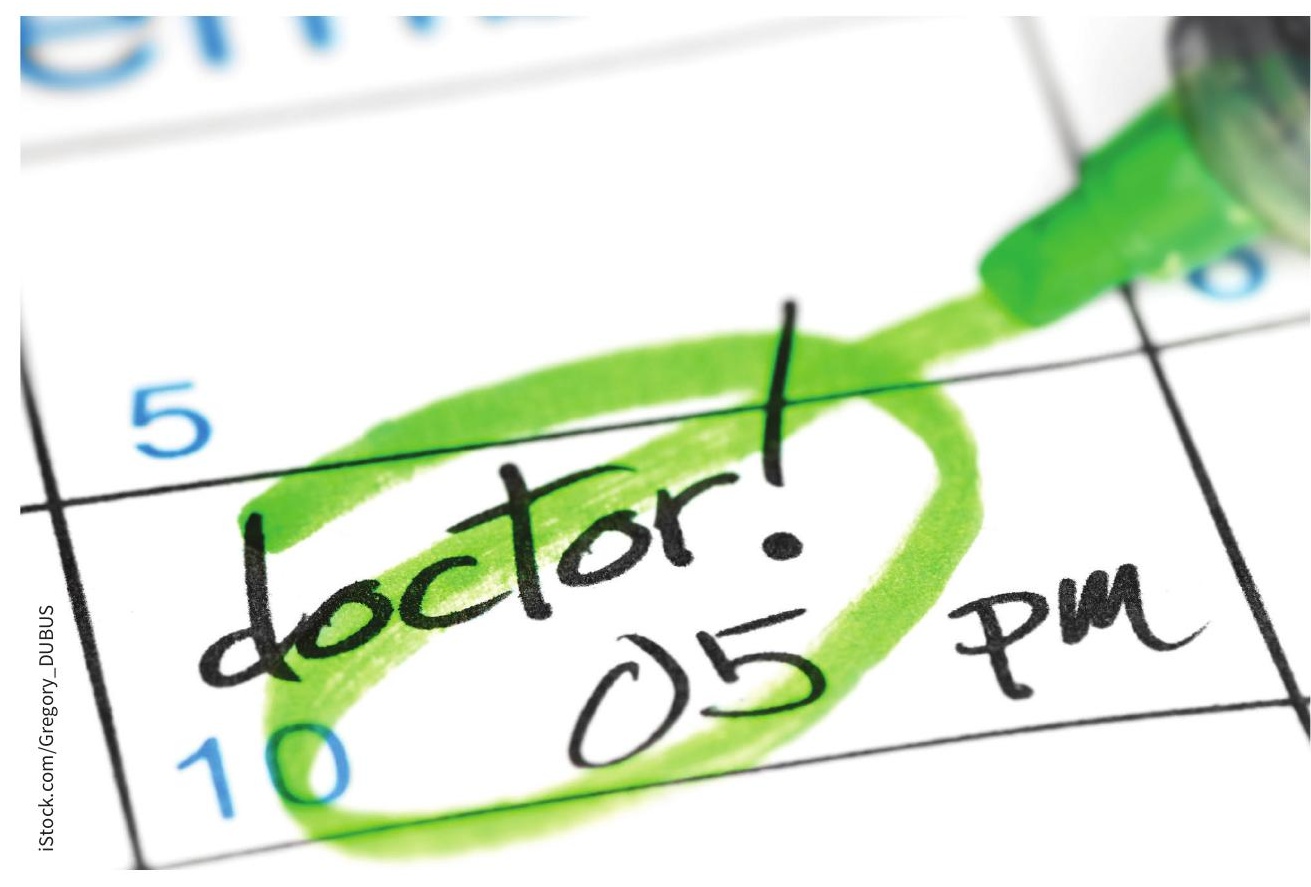

Research suggests clinics could do more to reduce no-shows without charging cancellation fees.

need to cancel or may be unable to reach the clinic, while others report that they don't feel obliged to keep appointments because they feel disrespected by the health care system. One person posted on a Healthy Debate forum, "Everyone's time is valuable. When the doctor makes me wait, there are consequences too. Why there are two standards in the situation?"

Provincial medical regulatory colleges generally leave it to a doctor's discretion to decide when and how much to charge for missed appointments, although some provide ethical guidelines; for example, Ontario doctors must consider a patient's ability to pay and Quebec physicians must be able to prove they couldn't fill the time with other professional activities.

However, research suggests that noshow rates could be reduced merely by providing more same-day or next-day bookings and appointment reminders. In an analysis of National Health Service data, data scientist Steven Black noted that same-day appointments accounted for just $2 \%$ of no-shows, despite these appointments being the most common. Meanwhile, appointments booked 15 days or more in advance accounted for nearly a third of no-shows. Canadian studies have likewise found the risk of no-shows increases the further in advance clinics book patients.

"The straight-up reason why there are so many no-shows, in my view, is because often people need to wait so long to get an appointment," Hampton says. The longer people wait, the more likely their health status will change, other obligations will come up, or they will simply forget.

In British Columbia, the number of missed appointments "seems to have gotten slightly better in the last several 
years," says Dr. Kathleen Ross, president of Doctors of BC. Ross credits an online training module in advanced access with this improvement. The program teaches doctors how to reserve around $50 \%$ of their appointments for same-day or nextday bookings. To be successful, doctors need to analyze booking data to figure out the times and days that tend to be busier, and they may need to extend their hours on some days, she explains.

However, Ross notes that advanced access is not possible for every clinic, especially those with high proportions of chronic and complex patients who require routine appointments. "It's not a one size fits all," she says.
Appointment reminders may also help reduce the rate of no-shows, but that's easier said than done. Since 2018, Health PEl's obstetrics and gynecology clinic in Charlottetown has reduced no-shows from highs around 80 per month to about 25 per month by calling patients with reminders the day before appointments. According to clinic manager Carol Sellar, "it creates a lot of work on our end because not only have you taken time our of your normal routine to make the reminder call, you're now scrambling to fill that appointment and calling for other people if they cancel."

Sellar says privacy issues stand in the way of clinics using automated reminders. "An automated call from your GP's office might be okay but it might get touchy if it's from an obstetric clinic," she explains. Calling the patient directly confirms that they receive the information, rather than a partner or friend, Sellar says.

Dr. Sohail Gandhi, president of the Ontario Medical Association, has set up automated email notifications for his patients, but says meeting the legal requirements to send the notifications wasn't easy. "It's truly time consuming, almost painful, because you have to get consents from all your patients saying they're willing to accept that their personal information will be sent over email," he says.

Wendy Glauser, Toronto, Ont. 